\title{
Sensitivity of annual and seasonal reference crop evapotranspiration to principal climatic variables
}

\author{
G T PATLE ${ }^{1, *}$ and D K Singh ${ }^{2}$ \\ ${ }^{1}$ Department of Soil and Water Engineering, College of Agricultural Engineering and PHT, \\ Ranipool 737135, India. \\ ${ }^{2}$ Water Technology Centre, Indian Agricultural Research Institute, New Delhi 110012, India. \\ ${ }^{*}$ Corresponding author. e-mail: gtpatle77@gmail.com
}

Reference evapotranspiration $\left(\mathrm{ET}_{0}\right)$ represents the evaporative demand of the atmosphere and depends on climatic parameters such as radiation, air temperature, humidity, and wind speed. Relative role of climatic parameter of $\mathrm{ET}_{0}$ varies from one climate to another and within the climate, and depends on the location and time. Sensitivity analysis was conducted and sensitivity coefficients were determined to evaluate the impact of principal climatic parameters on $\mathrm{ET}_{0}$ in Karnal district of India. Mean monthly $\mathrm{ET}_{0}$ and yearly $\mathrm{ET}_{0}$ from 1981 to 2011 were estimated from FAO-56 Penman-Monteith equation using the daily climate data collected from Central Soil Salinity Research Institute, Karnal. Results showed that seasonal and annual $\mathrm{ET}_{0}$ were most sensitive to maximum temperature followed by sunshine hours. However, wind speed, relative humidity, and minimum temperature had varying effect on mean $\mathrm{ET}_{0}$. After maximum temperature and sunshine hours, $\mathrm{ET}_{0}$ was more sensitive to wind speed followed by relative humidity and minimum temperature in summer. In monsoon, after maximum temperature and sunshine hours, $\mathrm{ET}_{0}$ was more sensitive to minimum temperature followed by relative humidity and wind speed. However, in winter, after maximum temperature and sunshine hours, $\mathrm{ET}_{0}$ was more sensitive to relative humidity followed by wind speed and minimum temperature. The study suggests that the climate variability would affect reference $\mathrm{ET}_{0}$; however, its impact on $\mathrm{ET}_{0}$ would be different for different parameters.

\section{Introduction}

Evapotranspiration is an important component of hydrologic cycle in semi-arid region. It represents the evaporative demand of the atmosphere at a given location and time. Water requirements of crops are generally estimated from reference crop evapotranspiration $\left(\mathrm{ET}_{0}\right)$. Accurate estimation of crop evapotranspiration is essential for irrigation scheduling and water resources management. Reference crop evapotranspiration depends on climatic parameters such as radiation, air temperature, humidity, and wind speed representing the evaporative demand of the atmosphere at a given location and time, and refers to evapotranspiration rate from a reference surface, not short of water (Allen et al. 1998). Different approaches varying from the empirical to physical base are used for the estimation of the reference crop evapotranspiration (Bakhtiari and Liaghat 2011; Kumar et al. 2012). The PenmanMonteith method (Allen et al. 1998) is widely used for studying of $\mathrm{ET}_{0}$ (Goyal 2004; Wang et al. 2006; Tong et al. 2007; Liang et al. 2008; Bakhtiari and Liaghat 2011). Global warming and associated changes in climate are expected to affect the climatic parameters to varying degrees. This in turn would affect the reference $\mathrm{ET}_{0}$. Sensitivity analysis is carried out to evaluate the role of each climate variable used in the computation of reference crop evapotranspiration (Saxton 1975). Sensitivity analysis quantifies the variations in output of a model

Keywords. Climatic variability; coefficients; evapotranspiration; sensitivity analysis; Penman-Monteith. 
with respect to variation in the model parameters (Saltelli et al. 2004). Sensitivity analysis is important to understand the connection between climatic conditions and $\mathrm{ET}_{0}$ variability and between data availability and estimation accuracy of $\mathrm{ET}_{0}$ (Gong et al. 2006). Normally sensitivity analysis is carried out by plotting the relative changes in dependent variable against the relative changes in independent variable. Sensitivity analysis can also be done by determining sensitivity coefficient, which is normally defined as increase/decrease in dependent variable per unit increase in independent variable. Sensitivity coefficient derived from observed data may be used to estimate $\mathrm{ET}_{0}$ for areas where detailed meteorological records are lacking (Liang et al. 2008). Sensitivity of reference crop evapotranspiration to climatic variability has been investigated by various researchers. These are presented in table 1 .
In this study, an attempt was made to analyze the sensitivity of reference crop evapotranspiration to the climatic variability in an agriculturally dominant district of Karnal under semi-arid region in Trans-Indo-Gangetic plains of India, which is under intensive agriculture cultivation. Most widely used FAO Penman-Monteith method was used to evaluate the sensitivity of computed $\mathrm{ET}_{0}$ to principal climatic parameter.

\section{Materials and methods}

\subsection{Study area}

The analysis was performed in Karnal district, India. This district is a part of Trans-Indo-Gangetic plains of India and is located between $29^{\circ} 25^{\prime}-$ $29^{\circ} 59^{\circ} \mathrm{N}$ latitudes and $76^{\circ} 27^{\circ}-77^{\circ} 13^{\prime} \mathrm{E}$ longitudes.

Table 1. Sensitivity of ET $T_{0}$ to climatic parameters.

\begin{tabular}{|c|c|c|}
\hline Authors & Country & $\begin{array}{l}\text { Sensitivity of } \mathrm{ET}_{0} \text { in relation to } \\
\text { climatic parameter }\end{array}$ \\
\hline Goyal (2004) & Arid region of western Rajasthan in India & $\begin{array}{l}\text { Most sensitive to maximum temperature } \\
\text { followed by net solar radiation and } \\
\text { wind speed }\end{array}$ \\
\hline Saxton (1975) & Western Iowa in USA & Most sensitive to net radiation \\
\hline Liang et al. (2008) & Tao's river basin of north-eastern China & $\begin{array}{l}\text { Most sensitive to Relative humidity } \\
\text { followed by sunshine hours, wind speed } \\
\text { and air temperature }\end{array}$ \\
\hline Gong et al. (2006) & Yangtze River, China & $\begin{array}{l}\text { Most sensitive to relative humidity } \\
\text { followed by shortwave radiation, } \\
\text { air temperature, and wind speed }\end{array}$ \\
\hline Bakhtiari and Liaghat (2011) & $\begin{array}{l}\text { Kerman Province in southeast } \\
\text { semi-arid region of Iran }\end{array}$ & $\begin{array}{l}\text { Most sensitive to vapour pressure deficit } \\
\text { followed by wind speed }\end{array}$ \\
\hline Porter et al. (2012) & Bushland in Texas in USA & $\begin{array}{l}\text { Most sensitive to wind speed and air } \\
\text { temperature followed by incoming } \\
\text { shortwave radiation }\end{array}$ \\
\hline Irmak et al. (2006) & $\begin{array}{l}\text { Arid, sub-humid, coastal humid, } \\
\text { inland humid and island of USA } \\
\text { (Scottsbluff, Nebraska, and Bushland, } \\
\text { Texas, Santa Barbara, California, } \\
\text { Fort Pierce, Florida, Rockport, } \\
\text { Missouri, Nebraska, and Twitchell Island }\end{array}$ & $\begin{array}{l}\text { Most sensitive to vapour deficit followed } \\
\text { by wind speed }\end{array}$ \\
\hline Ambas and Baltas (2012) & Florina of Western Macedonia of Greece & $\begin{array}{l}\text { Most sensitive to solar radiation with } \\
\text { highest sensitivity coefficient, followed } \\
\text { by temperature, wind speed and } \\
\text { relative humidity }\end{array}$ \\
\hline Sergio et al. (2014) & Spain & $\begin{array}{l}\text { Relative humidity, wind speed, and } \\
\text { maximum temperature had stronger } \\
\text { effects on } \mathrm{ET}_{0} \text { than sunshine duration } \\
\text { and minimum temperature indicating } \\
\text { that aerodynamic component has more } \\
\text { importance than radiative component to } \\
\text { determine the atmospheric evaporative } \\
\text { demand in Spain }\end{array}$ \\
\hline
\end{tabular}


Total geographical area of the district is 2520 $\mathrm{km}^{2}$. The study area is agriculturally dominant with rice and wheat as major crops. The district is characterized by subtropical monsoon type climate with very hot summer and a very cold winter (Fujisaka et al. 1992). The normal annual rainfall of the district during 1981-2011 was $740 \mathrm{~mm}$ of which $80 \%$ occurred during the southwest monsoon (June-September). Average annual minimum and maximum temperatures are $16.99^{\circ} \mathrm{C}$ and $29.94^{\circ} \mathrm{C}$, respectively. The average annual relative humidity and wind speed are $65.74 \%$ and $86.16 \mathrm{~km} \mathrm{~d}^{-1}$. Mean monthly maximum and minimum temperature are $38.3^{\circ}$ and $6.5^{\circ} \mathrm{C}$ in the months of May and January, respectively. Soils of the district are alluvial in nature and vary from sandy loam to clay loam. District has flat topography with an average elevation of $240 \mathrm{~m}$ above the mean sea level.

\subsection{Data used and methodology}

Data for the period of 1981-2011 consisting of minimum and maximum temperature, relative humidity, wind speed, and sunshine hour collected from meteorological observatory of Central Soil Salinity Research Institute (CSSRI), Karnal were used for computation of reference evapotranspiration $\left(\mathrm{ET}_{0}\right)$. Reference surface is a hypothetical crop with an assumed height of $0.12 \mathrm{~m}$ having surface resistance of $70 \mathrm{~s} / \mathrm{m}$ and albedo of 0.23 resembling actively growing green grass of uniform height (Allen et al. 1998). We used the CROPWAT Package of the Food and Agricultural Organization (FAO) for estimation of $\mathrm{ET}_{0}$. CROPWAT model of FAO uses the FAO Penman-Monteith (Allen et al. 1998) equation, which is maintained as the sole standard method for the computation of $\mathrm{ET}_{0}$ from meteorological data. This equation was derived from the original Penman-Monteith equation, and the equations of the aerodynamic and surface resistance. In FAO Penman-Monteith equation, the saturation vapour pressure $\left(e_{s}\right)$ is derived from $T_{\max }$ and $T_{\min }$, while the actual vapour pressure $\left(e_{a}\right)$ is derived from the dew point temperature $\left(T_{\text {dew }}\right)$, from maximum $\left(R H_{\max }\right)$ and minimum $\left(R H_{\text {min }}\right)$ relative humidity, from the maximum $\left(R H_{\text {max }}\right)$, or from mean relative humidity $\left(R H_{\text {mean }}\right)$ (Allen et al. 1998). The net radiation, $R_{n}$, is the difference between incoming and outgoing radiation of both short and long wavelengths. The soil heat flux, $G$, is the energy that is utilized in heating the soil. It is positive when the soil is warming and negative when the soil is cooling. Soil heat flux is small compared to $R_{n}$ and is often ignored. The amount of energy gained or lost by the soil should theoretically be subtracted or added to $R_{n}$ when estimating evapotranspiration. However, in calculating net radiation, the effect of soil heat flux $(G)$ is ignored for daily calculations as the magnitude of the flux in this case is relatively small. The net radiation, expressed in MJ $\mathrm{m}^{-2}$ day $^{-1}$, is converted to $\mathrm{mm} /$ day (equivalent evaporation) in the FAO Penman-Monteith equation by using 0.408 as the conversion factor within the equation. In this method, evapotranspiration rate from a reference surface, with abundance of water, is considered as the reference crop evapotranspiration normally referred as reference evapotranspiration, and is denoted as $\mathrm{ET}_{0}$. The reference surface is a hypothetical grass reference crop with an assumed crop height of $0.12 \mathrm{~m}$, a fixed surface resistance of $70 \mathrm{~s} \mathrm{~m}^{-1}$ and an albedo of 0.23 . It resembles an extensive surface of green, well-watered grass of uniform height, actively growing and completely shading the ground. The fixed surface resistance of $70 \mathrm{~s} \mathrm{~m}^{-1}$ implies a moderately dry soil surface resulting from about a weekly irrigation frequency. Standardized reference evapotranspiration equation suggested by Walter et al. (2000) is given by equation (1). The FAO Penman-Monteith model (Allen et al. 1998) uses equation (2) for estimation of reference $\mathrm{ET}_{0}$.

$$
\begin{aligned}
& \mathrm{ET}_{0}=\frac{0.408 \Delta\left(R_{n}-G\right)+\gamma \frac{C_{n}}{T+273} u_{2}\left(e_{s}-e_{a}\right)}{\Delta+\gamma\left(1+C_{d} u_{2}\right)} \\
& \mathrm{ET}_{0}=\frac{0.408 \Delta\left(R_{n}-G\right)+\gamma \frac{900}{T+273} u_{2}\left(e_{s}-e_{a}\right)}{\Delta+\gamma\left(1+0.34 u_{2}\right)}
\end{aligned}
$$

where $\mathrm{ET}_{0}$ is reference evapotranspiration ( $\mathrm{mm}$ $\left.\mathrm{d}^{-1}\right), R_{n}$ is net radiation at the crop surface $\left(\mathrm{MJm}^{-2} \mathrm{~d}^{-1}\right), G$ is soil heat flux density (MJ m ${ }^{-2}$ $\left.\mathrm{d}^{-1}\right), C_{n}$ is numerator constant that changes with reference type and calculation time step $\left(\mathrm{K} \mathrm{mm} \mathrm{s}{ }^{3}\right.$ $\mathrm{Mg}^{-1} \mathrm{~d}^{-1}$ or $\left.\mathrm{K} \mathrm{mm} \mathrm{s}^{3} \mathrm{Mg}^{-1} \mathrm{~h}^{-1}\right), C_{d}$ is denominator constant that changes with reference type and calculation time step $\left(\mathrm{s} \mathrm{m}^{-1}\right), T$ is mean daily air temperature at $2 \mathrm{~m}$ height $\left({ }^{\circ} \mathrm{C}\right), u_{2}$ is wind speed at $2 \mathrm{~m}$ height $\left(\mathrm{m} \mathrm{s}^{-1}\right), e_{s}$ is saturation vapour pressure $(\mathrm{kPa}), e_{a}$ is actual vapour pressure $(\mathrm{kPa}), e_{s}-e_{a}$ is saturation vapour pressure deficit $(\mathrm{kPa}), \Delta$ is slope vapour pressure curve $\left(\mathrm{kPa}^{\circ} \mathrm{C}^{-1}\right)$ and $\gamma$ is psychrometric constant $\left(\mathrm{kPa}^{\circ} \mathrm{C}^{-1}\right)$.

In equation (2), psychrometric constant is estimated using equation (3)

$$
\gamma=\frac{C p P}{\varepsilon \lambda}=0.665 \times 10^{-3} P
$$

where $\gamma$ is psychrometric constant $\left[\mathrm{kPa}^{\circ} \mathrm{C}^{-1}\right], P$ is atmospheric pressure, $\lambda$ is latent heat of vapourization, $2.45\left[\mathrm{MJ} \mathrm{kg}^{-1}\right], C p$ is specific heat at constant pressure and its value for average atmospheric condition is $1.01310^{-3}$ [MJ kg ${ }^{-1}{ }^{\circ} \mathrm{C}^{-1}$ ], $\varepsilon$ is ratio molecular weight of water vapour/dry air $=0.622$. Values for the psychrometric constant as a function 
of altitude are available in FAO 56 for use with CROPWAT.

Equation (2) can be used to compare the evapotranspiration at different periods of the year or in other regions and estimate the evapotranspiration of other crops (Allen et al. 1998).

In FAO Penman-Monteith, crop coefficient approach is used to estimate crop evapotranspiration $\left(\mathrm{ET}_{\mathrm{c}}\right)$ from reference crop evapotranspiration $\left(\mathrm{ET}_{0}\right) \cdot \mathrm{ET}_{0}$ is multiplied by crop coefficient to get the $\mathrm{ET}_{\mathrm{c}}$. The crop coefficient, $K c$, is the ratio of the crop $\mathrm{ET}_{\mathrm{c}}$ to the reference $\mathrm{ET}_{0}$, and it represents an integration of the effects of crop height, albedo, canopy resistance, and evaporation from soil that distinguish the crop from reference grass. $\mathrm{ET}_{0}$ represents an index of climatic demand whereas $K c$ predominately depends on crop characteristics and to a limited extent on climate. This enables the transfer of standard values for $K c$ between locations and between climates. This is the reason for the global acceptance and usefulness of the crop coefficient approach. If crop coefficient approach is used, then there is no need to change the $C_{n}$ and $C_{d}$ as the $\mathrm{ET}_{0}$ of reference crop is converted into $\mathrm{ET}$ of taller crop by multiplying it with crop coefficient.

Evapotranspiration estimated from the FAO Penman-Monteith equation provides a standard to which ET in different periods of the year and in other regions can be compared and to which the evapotranspiration from other crops can be related (Pereira 2007). Mean daily and seasonal $\mathrm{ET}_{0}$ for the period of 1981-2011 were estimated from mean values of climatic parameters using equation (1). The daily values of $\mathrm{ET}_{0}$ were added to get the seasonal and annual values of $\mathrm{ET}_{0}$. This was referred to as base line $\mathrm{ET}_{0}$ and mean values of climatic parameters were referred to as base line values. Sensitivity analysis was done by varying the magnitude of climatic parameters namely temperature, wind speed, sunshine hours, and relative humidity one at a time by $\pm 5 \%, \pm 10 \%, \pm 15 \%$ and $\pm 20 \%$ over the base line values of climatic parameters (table 2).

\subsection{Sensitivity coefficients}

Sensitivity coefficients were calculated to measure sensitivity of calculated reference $\mathrm{ET}_{0}$ to each climatic parameter using the method described in existing literature (Beven 1979; Gong et al. 2006; Liang et al. 2008). Normally, the results of sensitivity analysis are shown by plotting a curve between relative changes in a dependent variable and relative changes of an independent variable (Liang et al. 2008). For multi-variable models like Penman-Monteith method, different variables have different dimensions and different ranges of values, which make it difficult to compare the sensitivity by partial derivatives. To overcome this, a non-dimensional form of the sensitivity coefficient (Gong et al. 2006) is used (equation 4).

$$
S v_{i}=\lim _{\Delta V_{i} \rightarrow 0}\left(\frac{\Delta \mathrm{ET}_{0} / \mathrm{ET}_{0}}{\Delta V_{i} / V_{i}}\right)=\frac{\delta \mathrm{ET}_{0}}{\delta V_{i}} * \frac{V_{i}}{\mathrm{ET}_{0}} .
$$

where $S v_{i}$ is the sensitivity coefficient for the $i$ th variable and $V$ is the climate variable analysed. A positive or negative sensitivity coefficient indicates that $\mathrm{ET}_{0}$ will increase or decrease with the increase

Table 2. Mean value of principal climate parameters (1981-2011).

\begin{tabular}{llccccc}
\hline Season & Month & $T_{\min }\left({ }^{\circ} \mathrm{C}\right)$ & $T_{\max }\left({ }^{\circ} \mathrm{C}\right)$ & $R H(\%)$ & $W S\left(\mathrm{kmd}^{-1}\right)$ & $S S H(\mathrm{~h})$ \\
\hline \multirow{2}{*}{ Summer } & March & 12.6 & 27.5 & 64.0 & 88.0 & 8.2 \\
& April & 17.6 & 35.4 & 43.0 & 100.0 & 9.3 \\
& May & 23.0 & 38.3 & 43.0 & 136.0 & 9.3 \\
& June & 25.4 & 37.5 & 56.0 & 141.0 & 8.3 \\
& Mean & 19.7 & 34.7 & 51.5 & 116.3 & 8.8 \\
Monsoon & July & 26.2 & 33.8 & 76.0 & 116.0 & 6.5 \\
& August & 25.5 & 32.8 & 81.0 & 82.0 & 6.4 \\
& September & 23.1 & 32.6 & 77.0 & 67.0 & 7.5 \\
& October & 16.8 & 31.6 & 65.0 & 45.0 & 8.0 \\
& Mean & 22.9 & 32.7 & 74.8 & 77.5 & 7.1 \\
Winter & November & 11.3 & 27.3 & 63.0 & 45.0 & 7.3 \\
& December & 7.5 & 21.6 & 70.0 & 50.0 & 6.2 \\
& January & 6.5 & 18.6 & 76.0 & 73.0 & 6.0 \\
& February & 8.5 & 22.0 & 72.0 & 83.0 & 7.3 \\
& Mean & 8.5 & 22.4 & 70.3 & 62.8 & 6.7 \\
Annual & Mean & 17.0 & 29.9 & 66.0 & 86.0 & 7.5 \\
\hline
\end{tabular}

$T_{\min }$ : minimum temperature; $T_{\max }$ : maximum temperature; $R H$ : relative humidity; $W S$ : wind speed; $S S H$ : sunshine hours. 
or decrease of a climatic variable (Liang et al. 2008). The values of sensitivity coefficient $\left(S v_{i}\right)$ for a particular climatic parameter indicated the level of sensitivity of $\mathrm{ET}_{0}$ calculation to variation in that parameter. The larger the absolute sensitivity coefficient, the larger the effect of a given variable on $\mathrm{ET}_{0}$. Sensitivity coefficients were computed from the daily average values of 31 years of each climate variable. Thus each sensitivity coefficient is a daily average value of 31 years for each climate parameter for percent increase or decrease in respective climatic parameter. For example, to determine the sensitivity coefficients for the maximum temperature $\left(T_{\max }\right)$, the amount of increase or decrease in $\mathrm{ET}_{0}$ at 5\%,10\%,15\% and, $20 \%$ increase or decrease in maximum temperature were calculated as the difference between the computed mean $\mathrm{ET}_{0}$ and the new $\mathrm{ET}_{0}$ values for each season (summer, monsoon, and winter) and for whole year. The difference between the computed $\mathrm{ET}_{0}$ (with $5 \%$ increase or decrease in base $\mathrm{ET}_{0}$ ) and base $\mathrm{ET}_{0}$ was divided by the change in $T_{\max }$. Similarly, the sensitivity coefficients were determined for other climate parameters. The sensitivity coefficients on seasonal and annual basis were determined for better understanding of relative effect of each variable on $\mathrm{ET}_{0}$ in different seasons.

\section{Results and discussion}

Variations in mean monthly values of climatic parameters are shown in figure 1 . The mean minimum and maximum temperature were $17.0^{\circ}$ and
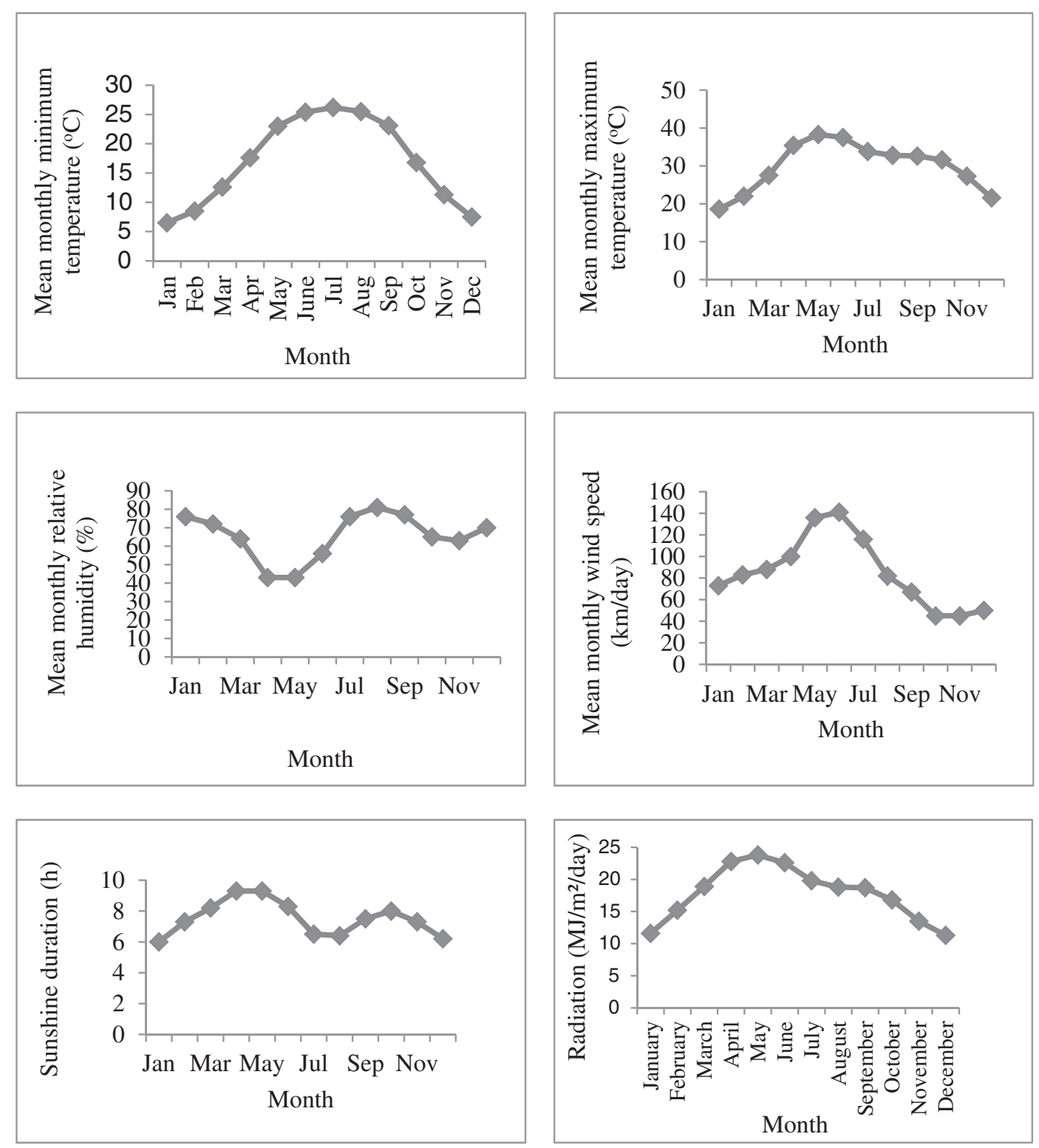

Figure 1. Mean monthly variations of major climatic parameters. 
$29.9^{\circ} \mathrm{C}$, respectively. The mean monthly relative humidity, wind speed and sunshine hours were $66 \%, 86 \mathrm{~km} \mathrm{~h}^{-1}$ and $7.5 \mathrm{~h}$, respectively. The lowest and highest mean monthly minimum temperatures were observed in the months of January and July. The lowest and highest mean monthly maximum temperatures were observed in January and May. The lowest and highest mean monthly relative humidity was in the month of May and August. Solar radiation was maximum in the month of May followed by April and June.

Table 3 shows the relative change in the annual and seasonal $\mathrm{ET}_{0}(\mathrm{~mm})$ due to percent change in each climate parameters. The relative change in each variable has varying effect on seasonal $\mathrm{ET}_{0}$. Change in $\mathrm{ET}_{0}$ due to increase or decrease in climatic parameters were compared with the mean $\mathrm{ET}_{0}$. The mean annual $\mathrm{ET}_{0}$ was $1372 \mathrm{~mm}$. The mean $\mathrm{ET}_{0}$ in summer, monsoon and winter were 643,505 , and $229 \mathrm{~mm}$, respectively. Increase in mean minimum temperature by $20 \%$, increased the summer $\mathrm{ET}_{0}$ by $2 \%$ (from 643 to $655 \mathrm{~mm}$ ). If the mean minimum temperature was reduced by $20 \%$, summer $\mathrm{ET}_{0}$ reduced by $1 \%$ (from 643 to $634 \mathrm{~mm}$ ). This indicates that the effect of increase in temperature was more on $\mathrm{ET}_{0}$ than the decrease in temperature. Variation in $\mathrm{ET}_{0}$ due to change in mean minimum temperature was more in monsoon season $(+5 \%$ for $20 \%$ increase in temperature and $-3 \%$ for $20 \%$ decrease in temperature).

This suggested that $\mathrm{ET}_{0}$ is more sensitive to mean minimum temperature in monsoon than in other seasons. In winter, the effect of increase or decrease in temperature on $\mathrm{ET}_{0}$ was $\leq 1$. Annual $\mathrm{ET}_{0}$ increased by $4 \%$ (from 1372 to $1424 \mathrm{~mm}$ ) for $20 \%$ increase in mean minimum temperature.

The effect of change in maximum temperature on $\mathrm{ET}_{0}$ was more prominent as compared to the other parameters. The effect of change in maximum temperature on $\mathrm{ET}_{0}$ was much more compared to other parameters. Increase in maximum temperature by $20 \%$ increased the $\mathrm{ET}_{0}$ by $12 \%$ in all the seasons including annual $\mathrm{ET}_{0}$. Decrease in mean maximum temperature by $20 \%$ decreased the $\mathrm{ET}_{0}$ by 9 to $10 \%$ in different seasons. Change in relative humidity influenced $\mathrm{ET}_{0}$ but the effect was less than the mean maximum temperature. The maximum change of $\mathrm{ET}_{0}$ was $\pm 5 \%$ in winter season for $\pm 20 \%$ change in maximum temperature. Reference evapotranspiration was more sensitive to relative humidity during winter followed by monsoon and summer seasons. Annual $\mathrm{ET}_{0}$ increased from 1372

Table 3. Changes in seasonal and annual $E T_{0}(\mathrm{~mm})$ due to change in principal climatic parameters.

\begin{tabular}{|c|c|c|c|c|c|c|c|c|c|}
\hline \multirow[b]{2}{*}{ Season } & \multicolumn{9}{|c|}{ Change in $\mathrm{ET}_{0}(\mathrm{~mm})$ due to percent change in climatic parameter } \\
\hline & $+5 \%$ & $+10 \%$ & $+15 \%$ & $+20 \%$ & Mean & $-5 \%$ & $-10 \%$ & $-15 \%$ & $-20 \%$ \\
\hline \multicolumn{10}{|c|}{ Minimum temperature $\left(T_{\min }\right)$} \\
\hline Summer & $645(0)$ & $648(1)$ & $651(1)$ & $655(2)$ & 643 & $640(0)$ & $638(-1)$ & $636(-1)$ & $634(-1)$ \\
\hline Monsoon & $510(1)$ & $516(2)$ & $522(3)$ & $528(5)$ & 505 & $500(-1)$ & $496(-2)$ & $492(-3)$ & $488(-3)$ \\
\hline Winter & $230(1)$ & $231(1)$ & $231(1)$ & $232(1)$ & 229 & $228(0)$ & $223(0)$ & $227(-1)$ & $227(-1)$ \\
\hline Annual & $1380(1)$ & $1391(1)$ & $1402(2)$ & $1424(4)$ & 1372 & $1365(-1)$ & $1358(-1)$ & $1351(-2)$ & $1347(-2)$ \\
\hline \multicolumn{10}{|c|}{ Maximum temperature $\left(T_{\max }\right)$} \\
\hline Summer & $661(3)$ & $681(6)$ & $700(9)$ & $720(12)$ & 643 & $625(-3)$ & $608(-5)$ & $591(-8)$ & $576(-10)$ \\
\hline Monsoon & $518(3)$ & $532(5)$ & $548(9)$ & $563(12)$ & 505 & $492(-3)$ & $479(-5)$ & $468(-7)$ & $457(-9)$ \\
\hline Winter & $235(3)$ & $242(6)$ & $249(9)$ & $256(12)$ & 229 & $223(-2)$ & $217(-5)$ & $211(-8)$ & $205(-10)$ \\
\hline Annual & $1409(3)$ & $1453(6)$ & $1493(9)$ & $1537(12)$ & 1372 & $1336(-3)$ & $1299(-5)$ & $1267(-8)$ & $1234-10$ \\
\hline \multicolumn{10}{|c|}{ Relative humidity } \\
\hline Summer & $637(-1)$ & $633(-1)$ & $628(-2)$ & $623(-3)$ & 643 & $647(1)$ & $651(1)$ & $656(2)$ & $660(3)$ \\
\hline Monsoon & $500(-1)$ & $495(-2)$ & $490(-3)$ & $485(-4)$ & 505 & $510(1)$ & $514(2)$ & $519(3)$ & $523(4)$ \\
\hline Winter & $227(-1)$ & $224(-2)$ & $220(-4)$ & $218(-5)$ & 229 & $232(1)$ & $234(2)$ & $237(4)$ & $239(5)$ \\
\hline Annual & $1361(-1)$ & $1347(-2)$ & $1336(-3)$ & $1321(-4)$ & 1372 & $1383(1)$ & $1394(2)$ & $1409(3)$ & $1420(3)$ \\
\hline \multicolumn{10}{|c|}{ Wind speed $(W S)$} \\
\hline Summer & $650(1)$ & $658(2)$ & $665(4)$ & $672(5)$ & 643 & $635(-1)$ & $627(-2)$ & $619(-4)$ & $611(-5)$ \\
\hline Monsoon & $506(0)$ & $509(1)$ & $511(1)$ & $513(2)$ & 505 & $503(0)$ & $501(-1)$ & $499(-1)$ & $497(-2)$ \\
\hline Winter & $231(1)$ & $233(2)$ & $235(3)$ & $237(4)$ & 229 & $227(-1)$ & $225(-1)$ & $223(-2)$ & $221(-3)$ \\
\hline Annual & $1383(1)$ & $1394(2)$ & $1405(2)$ & $1416(3)$ & 1372 & $1361(-1)$ & $1351(-2)$ & $1336(-3)$ & $1325(-3)$ \\
\hline \multicolumn{10}{|c|}{ Sunshine hour $(S S H)$} \\
\hline Summer & $653(2)$ & $664(3)$ & $674(5)$ & $685(7)$ & 643 & $632(-2)$ & $621(-3)$ & $611(-5)$ & $599(-7)$ \\
\hline Monsoon & $514(2)$ & $524(4)$ & $534(6)$ & $543(8)$ & 505 & $495(-2)$ & $486(-4)$ & $476(-6)$ & $466(-8)$ \\
\hline Winter & $232(1)$ & $235(3)$ & $238(4)$ & $241(5)$ & 229 & $227(-1)$ & $223(-2)$ & $221(-4)$ & $217(-5)$ \\
\hline Annual & $1394(2)$ & $1420(3)$ & $1442(5)$ & $1464(7)$ & 1372 & $1351(-2)$ & $1325(-3)$ & $1303(-5)$ & $1281(-7)$ \\
\hline
\end{tabular}

(Values in parentheses show the percent change). 



Figure 2. (a-d) Percent change in $\mathrm{ET}_{0}$ with respect to percent change in climatic parameter. 
to $1420 \mathrm{~mm}$ for $20 \%$ decrease in relative humidity. However, if relative humidity was increased by $20 \%, \mathrm{ET}_{0}$ decreased to $1361 \mathrm{~mm}$. $\mathrm{ET}_{0}$ was more sensitive to wind speed in summer followed by winter and monsoon season. The maximum change of $\pm 5 \%$ was observed in summer for a change of $\pm 20 \%$. Annual $\mathrm{ET}_{0}$ increased from 1372 to 1416 $\mathrm{mm}$ for $20 \%$ increase in wind speed. However, if wind speed was decreased by $20 \%, \mathrm{ET}_{0}$ decreased to $1325 \mathrm{~mm}$.

After maximum temperature, change in duration of sunshine hours affected the $\mathrm{ET}_{0}$ most. Maximum change of $\pm 8 \%$ was for $\pm 20 \%$ change in sunshine duration. The maximum change of $\pm 8 \%$ was observed in monsoon followed by summer $(7 \%)$ and winter (5\%). Annual $\mathrm{ET}_{0}$ increased from 1372 to $1464 \mathrm{~mm}$ for $20 \%$ increase in duration of sunshine hours. However, if duration of sunshine hours was decreased by $20 \%, \mathrm{ET}_{0}$ decreased to $1281 \mathrm{~mm}$. These results indicate that in all the seasons $\mathrm{ET}_{0}$ was more sensitive to mean maximum temperature followed by duration of sunshine hours. This suggests that the maximum temperature and duration of sunshine hours are major climatic parameters that control the $\mathrm{ET}_{0}$ in this region.

However, change in wind speed, relative humidity and minimum temperature had varying effect on relative change in $\mathrm{ET}_{0}$. After maximum temperature and sunshine hours, $\mathrm{ET}_{0}$ was more sensitive to wind speed followed by relative humidity and minimum temperature in summer. In monsoon, after maximum temperature and sunshine hours, $\mathrm{ET}_{0}$ was more sensitive to minimum temperature followed by relative humidity and wind speed. However, in winter after maximum temperature and sunshine hours, $\mathrm{ET}_{0}$ was more sensitive to relative humidity followed by wind speed and minimum temperature. In winter, $\mathrm{ET}_{0}$ was less sensitive to minimum temperature compared to other seasons. Goyal (2004) reported that, in the arid zone of Rajasthan in India, evapotranspiration was more sensitive to temperature followed by wind speed, solar radiation, and vapour pressure. Whereas, in our study area (Trans-Indo-Gangetic plain), after temperature, duration of sunshine hour has more effect on $\mathrm{ET}_{0}$. This may be due to the fact that the arid zone of Rajasthan falls in famous Thar Desert and, therefore, temperature and wind speed are relatively higher as compared to the TransIndo-Gangetic plain. Vapour pressure which represents relative humidity had least effect on $\mathrm{ET}_{0}$ in Rajasthan in contrast to Trans-Indo-Gangetic plains where wind speed and minimum temperature had least effect.

Table 4. Seasonal and annual sensitivity coefficient.

\begin{tabular}{|c|c|c|c|c|c|c|c|c|}
\hline \multirow[b]{2}{*}{ Season } & \multicolumn{8}{|c|}{ Change in $\mathrm{ET}_{0}$ due to percent change in climatic parameter } \\
\hline & $+5 \%$ & $+10 \%$ & $+15 \%$ & $+20 \%$ & $-5 \%$ & $-10 \%$ & $-15 \%$ & $-20 \%$ \\
\hline \multicolumn{9}{|l|}{$T_{\min }$} \\
\hline Summer & 0.08 & 0.10 & 0.10 & 0.11 & 0.04 & 0.06 & 0.06 & 0.07 \\
\hline Monsoon & 0.23 & 0.22 & 0.22 & 0.23 & 0.15 & 0.17 & 0.16 & 0.16 \\
\hline Winter & 0.11 & 0.06 & 0.07 & 0.05 & 0.11 & 0.05 & 0.03 & 0.05 \\
\hline Annual & 0.11 & 0.13 & 0.14 & 0.15 & 0.11 & 0.11 & 0.10 & 0.09 \\
\hline \multicolumn{9}{|l|}{$T_{\max }$} \\
\hline Summer & 0.58 & 0.58 & 0.60 & 0.61 & 0.58 & 0.55 & 0.53 & 0.60 \\
\hline Monsoon & 0.55 & 0.57 & 0.57 & 0.59 & 0.47 & 0.48 & 0.49 & 0.47 \\
\hline Winter & 0.53 & 0.59 & 0.59 & 0.57 & 0.53 & 0.53 & 0.52 & 0.52 \\
\hline Annual & 0.53 & 0.58 & 0.58 & 0.60 & 0.53 & 0.53 & 0.51 & 0.50 \\
\hline \multicolumn{9}{|l|}{$R H$} \\
\hline Summer & -0.16 & -0.16 & -0.15 & -0.15 & -0.12 & -0.14 & -0.14 & -0.13 \\
\hline Monsoon & -0.20 & -0.17 & -0.20 & -0.20 & -0.19 & -0.20 & -0.19 & -0.18 \\
\hline Winter & -0.20 & -0.25 & -0.23 & -0.23 & -0.22 & -0.22 & -0.25 & -0.24 \\
\hline Annual & -0.18 & -0.20 & -0.20 & -0.19 & -0.13 & -0.15 & -0.18 & -0.16 \\
\hline \multicolumn{9}{|l|}{$W S$} \\
\hline Summer & 0.23 & 0.23 & 0.23 & 0.23 & 0.27 & 0.24 & 0.24 & 0.25 \\
\hline Monsoon & 0.09 & 0.09 & 0.08 & 0.08 & 0.05 & 0.08 & 0.07 & 0.07 \\
\hline Winter & 0.22 & 0.15 & 0.17 & 0.18 & 0.20 & 0.16 & 0.17 & 0.18 \\
\hline Annual & 0.17 & 0.17 & 0.17 & 0.16 & 0.14 & 0.15 & 0.18 & 0.17 \\
\hline \multicolumn{9}{|l|}{$S S H$} \\
\hline Summer & 0.38 & 0.32 & 0.33 & 0.32 & 0.38 & 0.33 & 0.33 & 0.35 \\
\hline Monsoon & 0.35 & 0.35 & 0.38 & 0.37 & 0.46 & 0.37 & 0.40 & 0.38 \\
\hline Winter & 0.18 & 0.25 & 0.22 & 0.25 & 0.23 & 0.25 & 0.27 & 0.27 \\
\hline Annual & 0.30 & 0.32 & 0.32 & 0.31 & 0.40 & 0.37 & 0.34 & 0.33 \\
\hline
\end{tabular}


The changes in $\mathrm{ET}_{0}(\mathrm{~mm})$ with respect to percent change in each climate variable are presented in the figure $2(\mathrm{a}-\mathrm{d})$. Four separate lines are shown in each figure, which denote the change in $\mathrm{ET}_{0}$ for percent increase or decrease in each climate variable annually and seasonally. It is observed that $\mathrm{ET}_{0}$ response was linear with respect to percent change in all climate parameters with the exception of minimum temperature in winter season.

Table 4 represents the seasonal and annual changes in sensitivity coefficients. Ratios of change
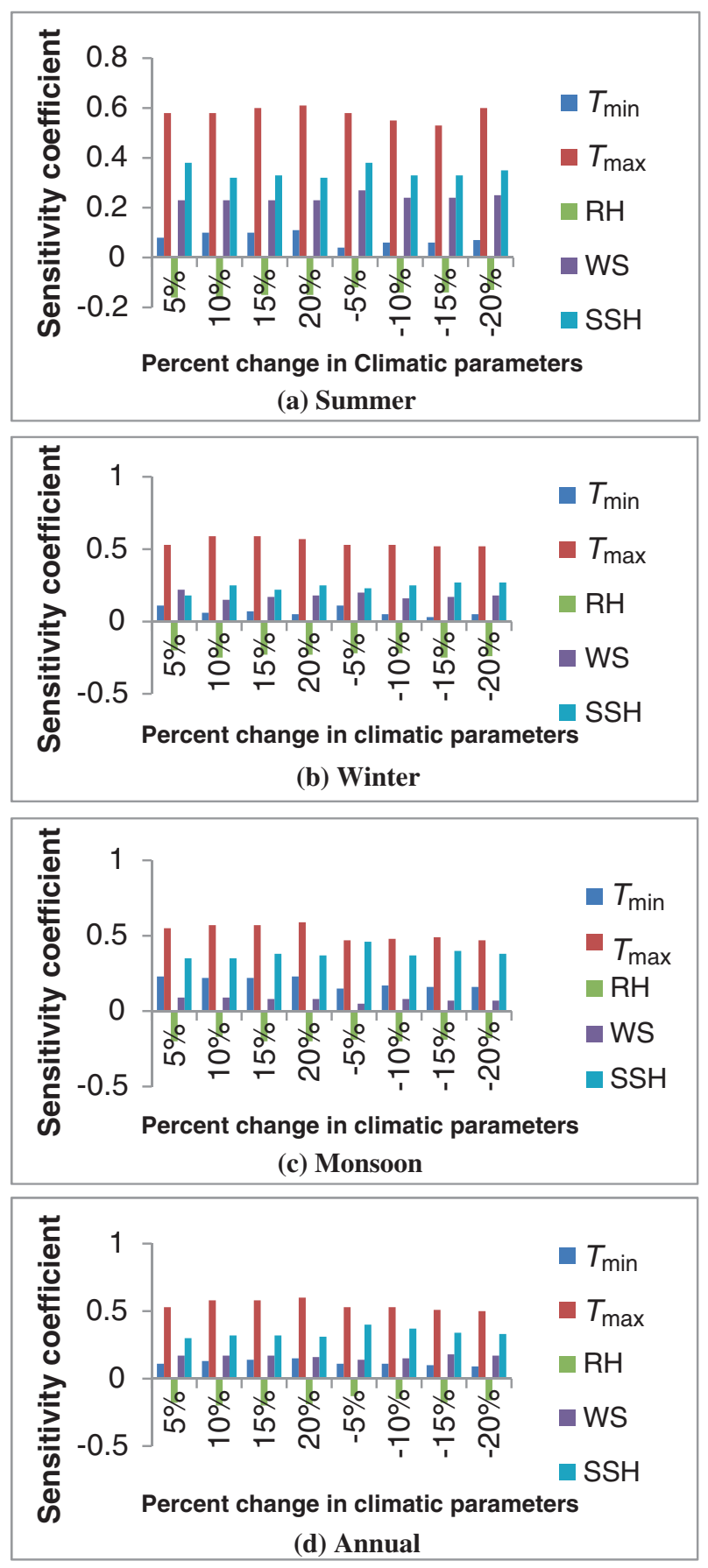

Figure 3. (a-d) Plot of sensitivity coefficient versus climate variable. in $\mathrm{ET}_{0}$ to change in climate variable were reflected as sensitivity coefficients. All sensitivity coefficients showed a large degree of fluctuations in all three seasons. The sensitivity of $\mathrm{ET}_{0}$ to the same climate variables showed significant differences within the seasons. In general, maximum temperature $\left(T_{\max }\right)$ had large sensitivity coefficients throughout the season and year. Coefficients of wind speed were lower during the monsoon and higher during the summer season. Maximum temperature and the sunshine hour (SSH) had the largest sensitivity coefficient during the year and in all three seasons. The magnitude of the sensitivity coefficients were ranked as $S_{T_{\max }}>S_{S S H}>S_{W S}>S_{R H}>S_{T_{\min }}$ in summer, $S_{T_{\max }}>S_{S S H}>S_{T_{\min }}>S_{R H}>S_{W S}$ in monsoon season, $S_{T_{\max }}>S_{S S H}>S_{R H}>S_{W S}>$ $S_{T_{\min }}$ in winter, and $S_{T \max }>S_{S S H}>S_{R H}>$ $S_{W S}>S_{T_{\min }}$ in a year. In which, $S$ stands for sensitivity coefficient and $T_{\max }$ is maximum temperature, $S S H$ is sunshine hours, WS is wind speed, $R H$ is relative humidity, and $T_{\min }$ minimum temperature. The sensitivity coefficients indicated that $\mathrm{ET}_{0}$ changes positively with maximum and minimum temperature, sunshine hour, and wind speed while reversely with the relative humidity. Plot of sensitivity coefficient versus climate variables for seasonal and annual time scale are shown in figure $3(\mathrm{a}-\mathrm{d})$.

\section{Conclusions}

Sensitivity analysis of daily reference evapotranspiration was conducted on principal climatic variables, namely minimum and maximum temperature, relative humidity, wind speed, and sunshine hours using daily data of 31 years (1981-2011) of Karnal district of Haryana state. The response of $\mathrm{ET}_{0}$ was linear to changes in all climatic variables with the exception of minimum temperature in winter season. Analysis revealed that mean seasonal and annual $\mathrm{ET}_{0}$ was more affected by maximum temperature followed by sunshine hours. However, wind speed, relative humidity, and minimum temperature had varying effects on mean $\mathrm{ET}_{0}$. After maximum temperature and sunshine hours, $\mathrm{ET}_{0}$ was more affected by wind speed, relative humidity, and minimum temperature in summer. In monsoon season, after maximum temperature and sunshine hours, $\mathrm{ET}_{0}$ was more affected by minimum temperature, relative humidity, and wind speed. However, in winter, after maximum temperature and sunshine hours, $\mathrm{ET}_{0}$ was more affected by relative humidity, wind speed, and minimum temperature. The change of temperature has slightly less effect on $\mathrm{ET}_{0}$ during winter season as compared to other seasons because mean temperature in winter is low. $\mathrm{ET}_{0}$ was less sensitive to the 
decrease in temperature than the increase in temperature. Seasonal and annual reference evapotranspiration showed an increasing trend with decrease in the relative humidity and vice versa. Study suggests that climate variability would affect reference crop evapotranspiration; however, its impact on $\mathrm{ET}_{0}$ would be different for different parameters. The study was carried out for Karnal district of Haryana using the data of only one station. However, the findings of the study will be applicable in the regions having similar climate. It would be interesting to see the results of the analysis in different districts in other regions of India. Procedures described in this paper can be used to carry out the analysis in other regions.

\section{Acknowledgements}

The authors are thankful to Central Soil Salinity Research Institute (CSSRI), Karnal, Haryana state (India) for providing the data for this study and Indian Agricultural Research Institute (IARI), New Delhi for providing the facilities for the research work.

\section{References}

Allen R G, Pereira L S, Raes D and Smith M 1998 Crop evapotranspiration - Guidelines for computing crop water requirements; FAO Irrigation and Drainage Paper 56, Rome 300.

Ambas V T and Baltas E 2012 Sensitivity analysis of different evapotranspiration methods using a new sensitivity coefficient; Global NEST J. 14(3) 335-343.

Bakhtiari B and Liaghat A M 2011 Seasonal sensitivity analysis for climatic variables of ASCE Penman-Monteith model in a semi-arid climate; J. Agric. Sci. Tech 13 1135-1145.

Beven K 1979 A sensitivity analysis of the PenmanMonteith actual evapotranspiration estimates; J. Hydrol. 44(3) 169-190.

Fujisaka S, Morris M L, Hobbs P R, Sharma H C, Singh R P, Chaudhary M K and Dhiman S D 1992 Wheat and rice, in Karnal and Kurukshetra districts, Haryana, India:
Farmers' practices, problems, and an agenda for action; CIMMYT.

Gong L, Xu C Y, Chen D, Halldin S and Chen Y D 2006 Sensitivity of the Penman-Monteith reference evapotranspiration to key climatic variables in the Changjiang (Yangtze River) basin; J. Hydrol. 329(3) 620-629.

Goyal R K 2004 Sensitivity of evapotranspiration to global warming: A case study of arid zone of Rajasthan (India); Agric. Water Manag. 69(1) 1-11.

Irmak S, Payero J O, Martin D L, Irmak A and Howell T A 2006 Sensitivity analyses and sensitivity coefficients of standardized daily ASCE-Penman-Monteith equation; J. Irrig. Drain. Eng. 132(6) 564-578.

Kumar R, Jat M K and Shankar V 2012 Methods to estimate irrigated reference crop evapotranspiration - a review; J. Water Sci. Tech. 66(3).

Liang L, Li L, Zhang L, Li J and Li B 2008 Sensitivity of PenmanMonteith reference crop evapotranspiration in Taoer River Basin of northeastern China; Chinese Geogr. Sci. 18(4) 340-347.

Pereira L S 2007 Relating water productivity and crop evapotranspiration; DER - Comunicações em Actas de Conferências, http://hdl.handle.net/10400.5/3539.

Porter D, Gowda P, Marek T, Howell T, Moorhead J and Irmak S 2012 Sensitivity of grass and alfalfa-reference evapotranspiration to station sensor accuracy; Appl. Eng. Agric. 28(4) 543-549.

Saltelli A, Chan K and Scott M 2004 Sensitivity analysis; John Wiley and Sons, New York.

Saxton K E 1975 Sensitivity analysis of the combination evapotranspiration equation; Agr. Meteorol. 15(3) 343-353.

Sergio M, Vicente-Serrano, Cesar Azorin-Molina, Arturo Sanchez-Lorenzo, Jesús Revuelto, Enrique Morán-Tejeda, Juan I López-Moreno and Francisco Espejo 2014 Sensitivity of reference evapotranspiration to changes in meteorological parameters in Spain; Water Resour. Res., doi: 10.1002/2014WR015427.

Tong L, Kang S and Zhang L 2007 Temporal and spatial variations of evapotranspiration for spring wheat in the Shiyang river basin in northwest China; Agr. Water Manag. 87(3) 241-250.

Walter I A, Allen R G, Elliott R, Jensen M E, Itenfisu D, Mecham B, Howell T A, Snyder R, Brown P, Eching S, Spofford T, Hattendorf M, Cuenca R H, Wright J L and Martin D 2000 "ASCE's Standardized Reference Evapotranspiration Equation"; Proceedings of 4th National Irrig. Symp., ASAE, Phoenix, AZ.

Wang H, Xu S and Sun L 2006 Effects of climatic change on evapotranspiration in Zhalong Wetland, Northeast China; Chinese Geogr. Sci. 16(3) 265-269. 